\title{
Status of Asiatic Wild Cat and its habitat in Xinjiang Tarim Basin, China
}

\author{
Ablimit Abdukadir ${ }^{1}$, Babar Khan ${ }^{1,2}$ \\ ${ }^{1}$ Xinjiang Institute of Ecology and Geography, Chinese Academy of Science, Urumqi, Xinjiang, China; ablmt $@$,ms.xjb.ac.cn \\ ${ }^{2}$ World Wide Fund for Nature Pakistan, Gilgit, Pakistan
}

Received 26 November 2013; revised 21 December 2013; accepted 27 December 2013

Copyright (C) 2013 Ablimit Abdukadir, Babar Khan. This is an open access article distributed under the Creative Commons Attribution License, which permits unrestricted use, distribution, and reproduction in any medium, provided the original work is properly cited.

\begin{abstract}
The Asiatic Wild Cat Felis silvestris ornata is regarded as "Least concerned" (LC) first, as "Vulnerable" (VU) and following "Endangered" (EN) and then "Critically endangered" (CR) species as finally and originally concentrative distribute in Xinjiang Tarim Basin region in northwest China. This paper provides comprehensive information on bio-morphology, habitat selectivity, environmental condition, habit, preyfeed source and every item of composition, and relationship among Wild Cat and domestic cat at presence investigated in 2004-2006 and 20112013 as especial study. The paper also illustrated some dynamical statistics of wild cat' pelt collection by national trade from three prefectures in the last $\mathbf{4 0}$ years. Briefing the results of indication that large scale and continuous openup land for cotton in unplanned, exploit petroleum and natural gas, misapply water and destroy desert vegetation, poaching and killing prey objectives, etc., of them long-term effects on plants functional density and qualities of the cat surviving habitat and productivity, whereas pressures of increasing human population to fragile desert ecosystem showed efficiency and desirable effects of the cat surviving.
\end{abstract}

Keywords: Asiatic Wild Cat; Tarim Basin;

Distribution; Habitat; Xinjiang

\section{INTRODUCTION}

In the worldwide about 23 species of small cats exist now [1]. These small cats are regarded as a geological relic species and were found save-keep-floors of the earlier-Pleistocene, that the small cats are comparatively primitive types and wild ancestries of domestic. Wild Cats were shared into three different groups-European Wild Cat Felis silvestris silvestris, African Wild Cat Felis silvestris lybica and Asiatic Wild Cat Felis silvestris ornata [2]. Really it seems to be classified into three subspecies for distinguished silvestris, lybica and ornata. Very clearly, European Wild Cat is almost distributed and occurs in Europe except for northern Europe; African Wild Cat is distributed and occurs in all African countries and south-western Asia regions. For Asiatic Wild Cat (coordinated local name in China is Wild Cat, Rustic Cat, Local Cat, Spotted Forest Cat, Spotted Steppe Cat, European Wild Cat, etc.) (in following text be abbreviated it "Wild Cat"), they were distributed and occur in middle and west Asia [3]. In China, the Wild Cat originally and concentratively distributes in Xinjiang Uygur Autonomous Region (in following text be abbreviated it "Xinjiang"), then rarely distributes in Gansu and Ninxia provinces. In Xinjiang, the cat only distributes in big desert the Tarim Basin of southern part of Xinjiang, then solitary distributes in Turpan Basin [4-8].

The beginning of the $60 \mathrm{~s}$ of the $20^{\text {th }}$ century their organization as the Comprehensive Expedition Team of Chinese Academy of Science while southern Xinjiang Wildlife Fauna as firstly investigated, submitted and demarcated Wild Cat's some real occur regions as distribution area and range only such as Yarkan (Sache) county, Kashkar (Kashi) of south-western fringe and Lop-nor lake region, Qarkilik (Ruoqiang) county, Qarqan (Qiemo) county of south-eastern fringe of Tarim Basin. Then there is not especially scientific project or observation presence until the beginning of the $90 \mathrm{~s}$ of the $20^{\text {th }}$ century, so still a point for filling the gaps to study. While Beijing workshop in CSG makes an important role in motive force and a new propel to the cat's study especial and planned a study project according to attendances propose. Following, Ablimit Abdukadir and Gao Xingyi made a special study work on the Wild Cat under project on "the 
Status Survey and Conservation of Lynx and other smallsized Cats in Xinjiang, China" (be listed into 80th project of IUCN/SSC "Wild Cat Conservation Action Plan") according to the cat condition in Xinjiang, China. This work was carried out on-the-spot investigation field work during the period of from August to September, 1996 and from October to November, 1998. Then, the project especial aid on Wild Cat continued from 1999 to 2001 and 2004 to 2006, except that we have carried on the study species of Felidae (5 species) in Xinjiang, China. At that period, we have obtained some systematic field data on investigation including large scale distribution, ecology, habitat and its condition, habits, population estimation and protection-utilization status etc. As first, from 1996, Xinjiang Institute of Biology, Pedology and Desert Research, Chinese Academy of Sciences and Hokkaido University of Japan established an international cooperation project for study on the cats in Xinjiang, China. Two-year study work relating to the cat's data bases on eco-biology and phylogenetic analyze including collecting samples from dead remains, skins, furs, feces, night soils, dropped hairs and feed remains with diet objective samples was analyzed. These samples were collected from different distribution areas such the Aksu Awat, Kuqar, Kashkar, Qarqan, Washshari, Qarkilik, Hotan, Niya, $33^{\text {th }}$ agricultural polk of Korla etc. Meanwhile, Wild Cat observational work is at which concentrate area about $500 \mathrm{~km}^{2}$ typical habitat in the lower reaches of Qarqan river basin. In that period we made another special cooperative scientific expedition and comparatively work between and within central Asia countries, including the Cat's distribution status in two big deserts of Xinjiang and Kazakhstan, winter ecology, habitat character and condition, sample collection for comparative research and classification [9-15].

In recent 3 years, e.g. from 2011 to 2013 we carry out the great project "Study on the habitat selectivity and population status of Asiatic Wild Cat in Xinjiang arid inland" from National Natural Science Foundation of China (NNSFC) as the second in order to further clear up the Wild Cat's surviving mechanisms with habitat selection in extremely arid environment (inland arid zone), and its closer relatives between local domestic cat, evolution and generation, original period and degree, population measures, living position and diversiform affects to wildcat living and habitat in this fragile ecosystem and noncomplete biological diversity. This group was organized by the Xinjiang Institute of Ecology and Geography, Chinese Academy of Sciences and WWF-Pakistan and this 4-season investigation field work was carried out 12 sampling areas to during the period of the January to December in every project year. As a results of comprehensive evaluation that connects with former materials, we confirm distribution range shape of Wild Cat which is large ellipse on Tarim Basin, and small ellipse in Turpan
Basin of Xinjiang, China [16] (Figure 1). As a sort out the data of our evaluation results we would report as follows.

\section{RESULT AND DISCUSSION}

\section{Status}

Studies on co-existence of wild cat with its closer relative, the domestic cat in the extremely arid environment (inland arid zone), its evolution, original period and degree, and position and affects on fragile ecosystem and biological diversity, XIEG CAS and the IUCN/SSC Cat Specialists Group conducted periodic field investigations during October-November 1999 and, for short intervals from 2000 to 2007. Our study endorses the previous findings to confirm the distribution of the wild cat in Tarim and Turpan basins of Xinjiang (Figure 1). The subspecies is least concern with declining population trend in its entire range. In China, it is a Class II animal with CR A1a status in Chinese Red List.

\section{MORPHOLOGICAL FEATURES}

At field work, we have obtain 12 pieces complete skins and 6 skulls as sample of Asiatic Wild Cat from 12 mixed in-spot investigation sample areas and concentrative distribution ranges from the south to north Tarim Basin, respectively. According to meterage and compare with kindly samples of the wildcat and domestic cat, we are gathered a concrete true statistical and in accordance measurement information on the wild cat as follows:

1) Bodily form similar to domestic cat, but thick and strong than that, not clear revealed difference among which male and female, mean body weight for adult within 3600 - $4100 \mathrm{~g}$, mean body length within $683-702$ $\mathrm{mm}$, tail length were within $260-360 \mathrm{~mm}$.

2) Different every sample with connected different parts of assai area in its body hair light brown and dorsal hair as visible part is deep gray (from Turpan) to deep brown (from Aksu and Awat) and light brown (female, from Hotan), respectively, the hair color of flanks of upper to lower is gradually revealed to light gray sand color to white, most irregularly-shape points and stripes revealed deep brown or light black is were densely covered in the body, the tuff bunches of ears deep brown but ears sharp black-brown frown, tail sharp black-brushy and lower is similar to lower front part of the body including the stomach and bowls colored by white. Wild Cat similar circumstances which with other desert animal's in morphological protruding features such as like as covered which sand color (protective coloration) adding with small brown and dark points and black line-spots. Moreover the four limb pads is covered by thickness densely and soft hair that clearly shown by a dwelling animal adopt in widely, aridly and fragile desert eco-environment, and 


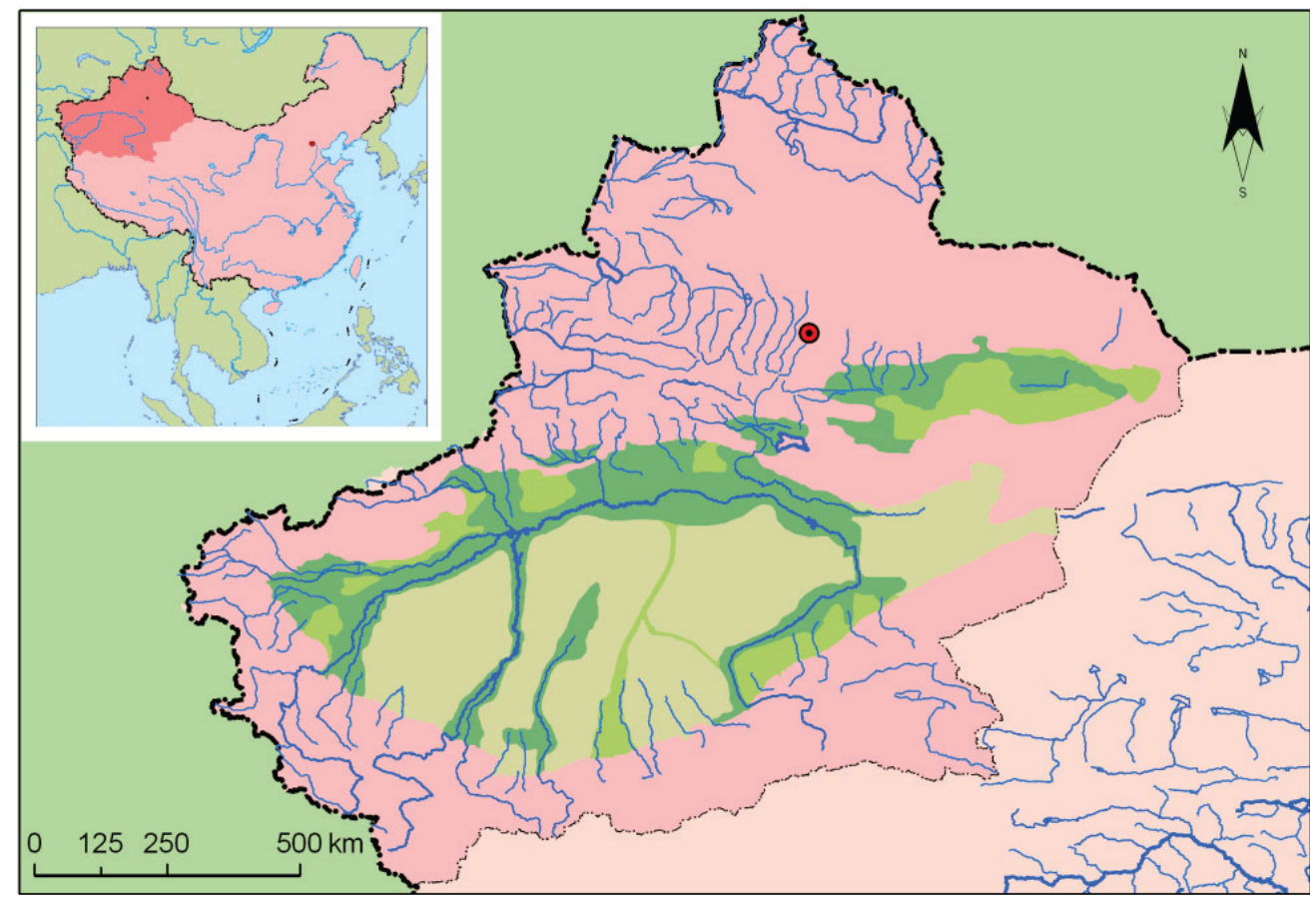

Figure 1. Map of study area showing distribution of wild cat (high and low density to potential: dense green, light green and sand color in range).

displaying adaptation themselves to circumstance of different thermo graphical climate at the day and night [17] (Figure 2).

3) Skulls were shorter and quick-quadrangled, this feature could be associated with magnitude of hear-puff bones and eye socket convex intensively. In addition to the upper split teeth be provided with relatively large an interior teeth leaves and a good teeth-sharps (Figure 3).

\section{HABITAT SELECTION}

As a large scale distribution area of Wild Cat, the Tarim Basin situated in between the south slope of Tianshan and northern slope of Kunlun-Altun mountain, total area of valley is more than $500,000 \mathrm{~km}^{2}$, east to west $1400 \mathrm{~km}$ long and north to south more than $500 \mathrm{~km}$ wide. As a centre part the basin, the Taklemakan Desert inside here about $330,000 \mathrm{~km}^{2}$, the biggest of its kind in China and second biggest shifting-sand desert of the entire world, basin average sea level were $900-1200 \mathrm{~m}$, of them Wild Cat's real distribution range about 210,000 $\mathrm{km}^{2}$. The Wild Cat distribution area geo-morphological relief is north-west part highest and its northern part including Turpan Basin and surrounding Lop-nor lake area were the lowest [18]. Tarim Basin's climate is aridly, sand-stormy and its temperature differ among day and night, annual rainfall rarely, only were 10 - $60 \mathrm{~mm}$, quantity of light and heat of sun-shining is an adequately, mean annual temperature were $10^{\circ} \mathrm{C}$, non-frost period extending to 200 days, in summer of some time on sand ground temperature reached to $50-60^{\circ} \mathrm{C}$. Another small but typical topographic distribution area, the Turpan Basin, it can to a certain degree as much as Tarim Basin, but extent some distinguished although it situated in between Tianshan Mountain (eastern), Komtag and Qoltag. The Turpan Basin's total area more than $50,000 \mathrm{~km}^{2}$, of them Wild Cat distribution range about $20,000 \mathrm{~km}^{2}$, sea level -154 (below zero $154 \mathrm{~m}$ ) to $500 \mathrm{~m}$ high, revealed typical continental inland warm-temperate desert zone climate, mean the absolute annual higher temperature is $47^{\circ} \mathrm{C}$, among the day to night air temperature are Figures $\mathbf{4}$ and 5.

More than 100 days it even occurs. General feature of situation of Turpan can distinguish: the spring in earlier, the summer heat-day longer and the autumn shorter. Mean annual temperature $12.1^{\circ} \mathrm{C}-14.9^{\circ} \mathrm{C}$, the highest temperature is $44^{\circ} \mathrm{C}$, annual rainfall $20-45 \mathrm{~mm}$, nonfrost period extending 190 - 230 days [19,20].

In Tarim Basin the Tarim River is regarded as famous river in the inner land of Centralasia, it divided and consisted by Hotan River, Keriya River, Yarkan River, Aksu River, Qarqan River, Konqi River, Kaydo River and lower bank of Bostan Lake (Bositonghu), Lop-nor Lake and Daxkol Lake (Dashihaizi). Around and bank-shore two side of these water system take shape not alike oasis and landscape (oasis, along bank green corridor, desertification cultivated area and desert). In this "green source" and "old wetland" of all riverbed grow up some plants community were haplotypically, occupy a domi- 


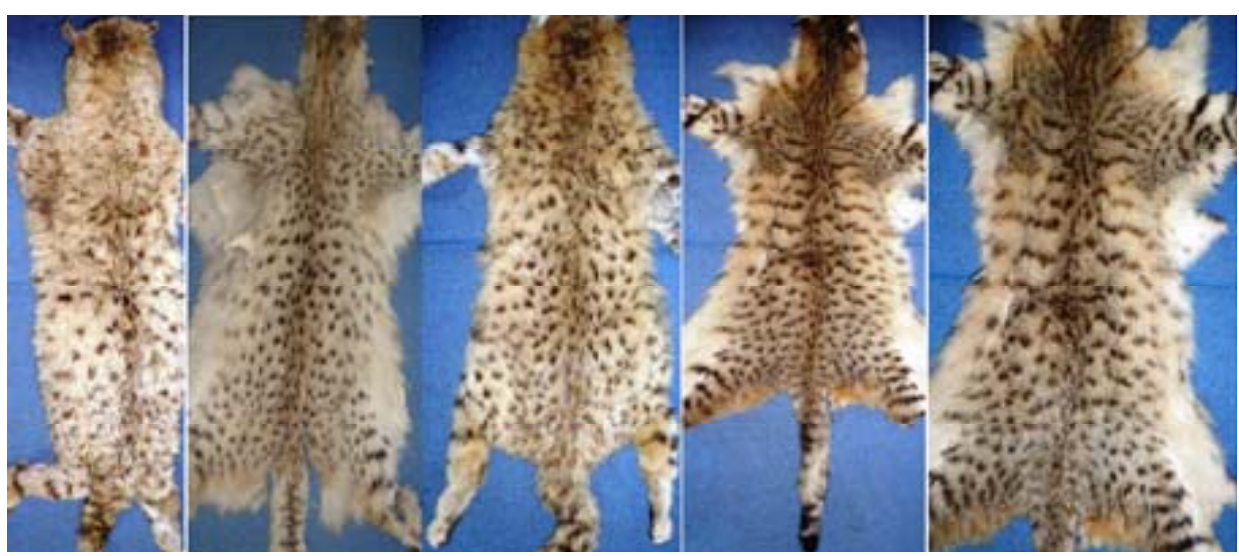

Figure 2. Color pattern and stripe-point structure of Asiatic Wild Cat assumable that relative living habitat condition.

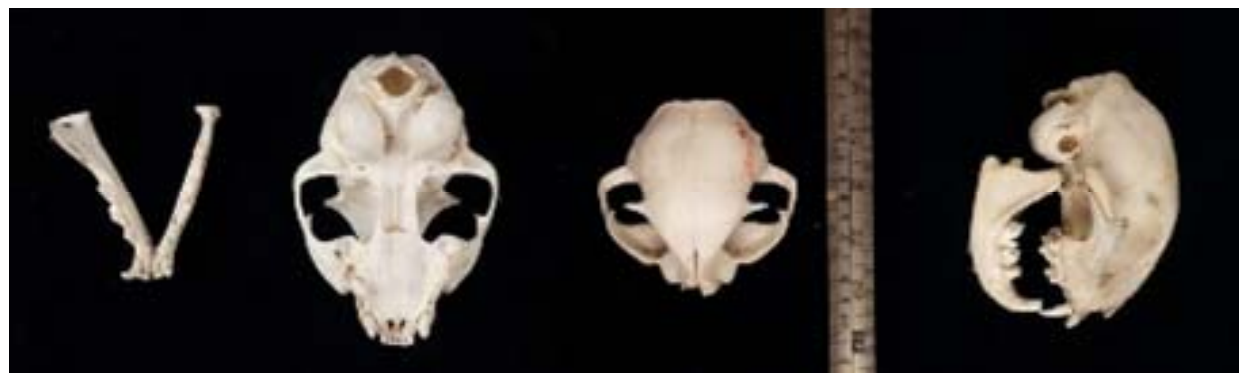

Figure 3. Skulls of Asiatic Wild Cat.

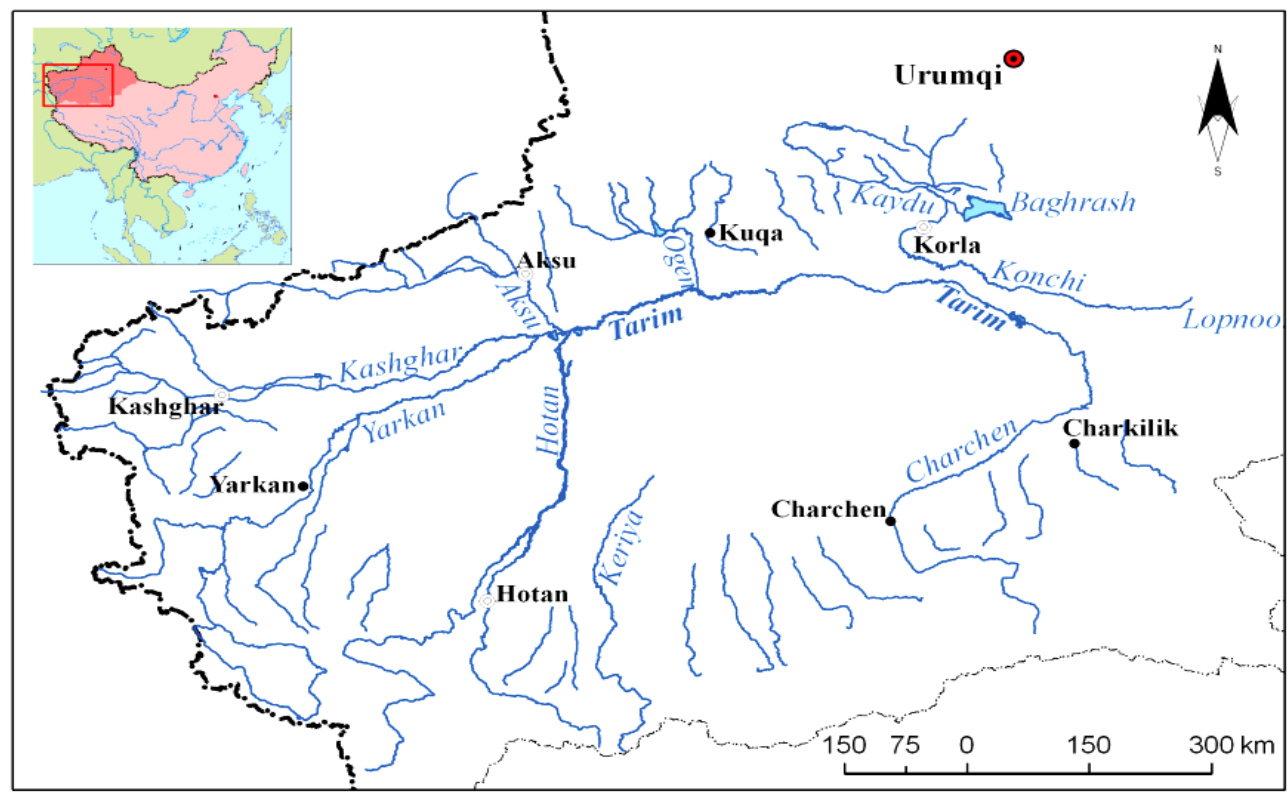

Figure 4. Map of Tarim River system in Tarim Basin, Xinjiang, China.

nant position plants are Phragmites communis, Tamarix, Populus diversifolia, Alhagi, Nitraria schoberi, Glycyrrhiza and Trachomitum lancifolium, etc. These composition of desert plants revealed as extensively, fragmentally and pointally distributed in different belt of the Tarim Basin. If keep a lookout or sectioning the basin it can take shape, for example, cultivating area-oasis-desert grassland-semi-desert and desert at one flood water filled area. Except for cultivated area, other landscape is just one ideal habitat for Wild Cat. At the upper reaches to middle reaches of any river Wild Cat could not distribute and not sufficient its activity because it another land- 


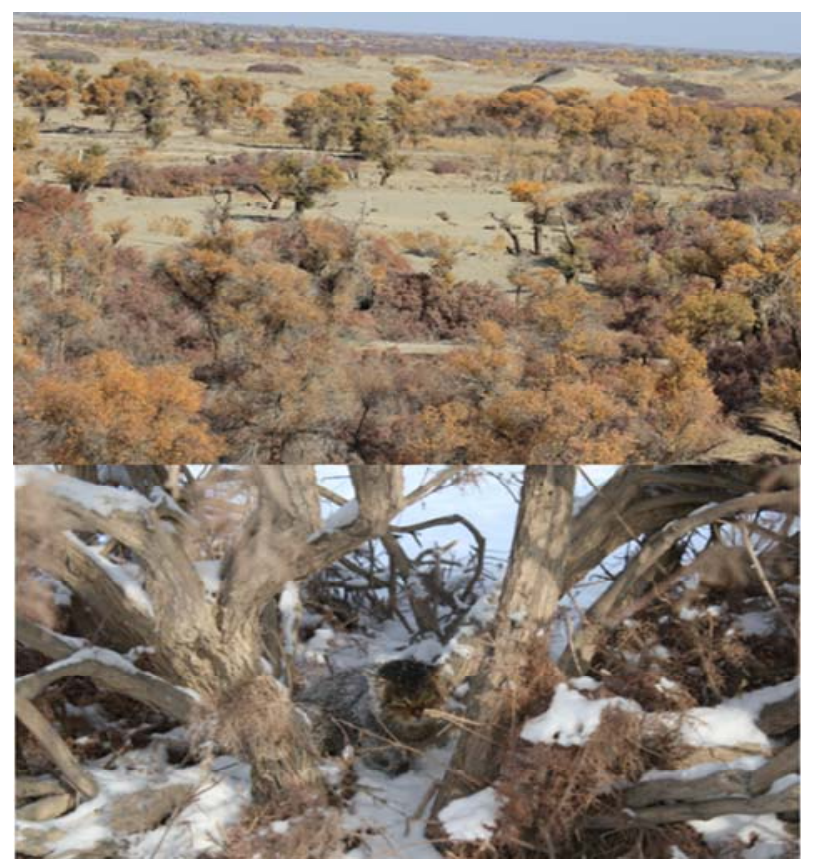

Figure 5. Main habitat landscape (above) and wintering under Tamarix trees of Wild Cat (below) in Xinjiang Tarim Basin.

scape — hard soil, cobble or stone desert or highest area human population or cultivation.

The Yarkan Hare/Tarim Hare Lepus yarkandensis/ tarimensis because living in same habitat with Wild Cat, distribution range just overlapping. Outside of Tarim Basin in more than $2000 \mathrm{~m}$ elevation which cobble desert, stone desert, egg-stone desert and mountainous-grassland area/or zone/or slope were distribution another catsChinese Mountain Cat (Desert Cat) Felis bieti in lower slope area and Pallas's Cat Felis manul in high hillmountainous.

In Turpan Basin distribution area, only typical sand desert which were covered which Saxaoul bush and Tamarix Community and population is an ideal habitat for Wild Cat. So three small cats of Felidae in Xinjiang have very closely but clearly provides with an appearance one replaces another [21].

\section{HABIT}

Occasionally, Wild Cat because more proceed in nocturnal as like as Felidae's other species. But its time and range is depending and variation in different seasonal change and conditions of richness of feed resources. In summer, Wild Cat its activities just balance with activity of Tarim Hare. Wild Cat meaningful strict to control its activity during the sun-rising and sun-setting because in firstly restricted by the Tarim Basin's especially geographical environment conditions, and secondly restricted by its mainly food objective-Tarim Hare's dailylife activities, frequencies and its appropriate habits.
Other way, there are for example of their adversarial competition among as natural enemies-Red Fox Vulpes vulpes, Domestic Cat Felis domesticus and Common Eagle Accipter gentiles (especially the mid of September to the mid of November), also human dimensions. Wild Cat almost no move outside activity itself to day time and winter. In the distribution area of Wild Cat no store up the snow, but the cat evenly resting in cavity nest and hide itself severe winter, cold and parasitic body and wounded disease to dead [21].

During the periods of 1994, 1995, 1996 and 2008 a respectively from local people, most recent few years due to kindly unknown reasons with which Tarim Hare's population numbers gradually decline thus not enough for feed for the cat even loiter to residential area attacking and catching domestic poultry and small animal, but to searching waste-food kindly at some times when it hungry. In 32 residential area of Tatirang of Qarqan (Qiemo) county and 13 residential area of Washshari of Qarkilik (Ruoqiang) county the Wild Cat to attack, catcheating or injure some same years old poultry.

In order to get their span of life conveniently such quench cat's thirst, feed and shelter, the cat were very most concentrate to move about in lower reaches of every branch river of two shore-side, Tarim River be in flooded but dried lands and around of new and old oasis. Wild Cat were dwelling on which rarely but high and large Populus tree, especially like were settle down on "a-half-living and a-half-dead" tree or with which hollow and cavitary Populus tree, wrap of Tamarix bush community and sand dune of river shores. At salinized whites soil, hard earth, non-vegetation desert and an environment haplotype landscapes may not be suit Wild Cat their living (evenly avoided itself). If an ideal habitat the cat shelter in which be abandon old residents or especial coquettish "Yardang" (in Uygur it mean is "an erosion landscape caused by wind and rain in the numerous years ago"). In Turpan distribution area, Wild Cat shelter in older local residential district, under densely Saxaoul bushes and around earth hole of "Kariz well". Whatever, which distribution area, Wild Cat even like its activities in abandon plough (uncultivated land), wasteland and nearby cultivated land as its soft sand parts, because there are relation to prey recource and supply to themselves. We suggest that Wild Cat's might be almost provided with a territorial kinship range or home range for long term and steady. Its opportunity for gain feed not only depending hunt habit, ability and shelter condition, but also be strict restriction directly whether access to prey objectives and food density in abound/richness, distribution and intensive activities frequencies [22].

During the 1994-1996, the winter of 2006 and summer of 2008, we survived on observation habitat condition, habitat selection and use and some habit of Wild Cat in 
the lower reaches of Qarqan river valley and Yarkan river valley (total area about $1000 \mathrm{~km}^{2}$ ), them has be observed it feed hunting activities, urine-mark presence and target objectivities, as well as collected its dropping remains and night-soils, end-feed remains, bite remains, remain of stomach and intestines of carcass, etc as a data to analyzed, as well as related to attempt presence of lure for catching a live, visit peasant-herdsman and local hunters, emphasized possibility on collect such hare-rodent target objectives. Of them particularly emphasized collect out skull, foot, hair, incomplete skeleton of target hare-rodent-birds in cat droppings (Figure 6).

According to item analysis results on feed, the cat's first mainly objective is Tarim Hare Lepus yarkandensis/ tarimensis (take up $74.2 \%$ in items). Other items consisting which Jerboas Meriones species, Gerbils Dipodidae species, poultry and small birds, livestock, Cardiocranius species, Agamidae species and Phrymocephalus species (sand lizards) take up 15\%,3.1\%, 2.5\%, 2.3\%, $1.3 \%, 0.9 \%$, respectively. Foot pads of Wild Cat covered by densely thick hair to be convenient to avoiding hot on sand desert in summer, as well as to be an advantage to closing to by noiseless its prey. For tracks chain of Wild Cat it can be find and distinguish with hare an irregular shallow however hare tracks deep and regular long chain on sand. In summer, Wild Cat its activity continued about 12 hours, mean is begun to afternoon 6 - 7 o'clock to second day 8 - 9 o'clock. At which weather of windstorm and cool, sometime to possible change its activity. Summer the Tarim Hare enter twice production, that mating season the cat mainly catch and meat Gerbils, Jerboas and some sand lizards (investigated and analyzed results on density is $58.8 \%, 35.4 \%$ and $5.8 \%$, respectively). The February to May and September to November Wild Cat's mainly catch as predate Tarim Hare. Actually, Wild Cat attend breeding activity frequently continued December to February. While female make an offer of cross for with male imitative. If that time still no results on cross, it activity repeat once seven days later, but the cat only will be produce once in one year. Pregnancy period about 60 days, even produce 2 - 3 kitten, initial kitten appear in black [22].

\section{RESOURCES, UTILIZATION AND PROTECTION}

Before the 50 s years of the $20^{\text {th }}$ century, Wild Cat is one resource member in Felidae and commonly and widely occur in southern Xinjiang primeval densely/ naturally bush desert and oasis including along each reaches of all rivers.

According to our investigation, visit and statistic materials, the period of 1955-1994 for 40 years, as importance distribution area and also production area of southern Xinjiang's three regions (Bayingolin Mongol Auto- nomous Oblast, Aksu and Hotan regions, concerning about 16 counties) Wild Cat traditionally to be hunted for skin collect to purchase to foreign and local trade of total 120,000 pelts, of them foreign trade organization to be collect from local people total registered skin (solid in national local trade) about 22,350 pelts (Table 1). Due to excessive hunting for fur trade, including its environment and habitat be subjected to destroyed by human, in addition a movements continued as political such as "Big leap Forward", "Weeding four harmful animals" (mean is to eliminated crow, sparrow, rat and fly), "Given rise to cultivate land and open up wasteland", "Intensively use chemical for wedding harmful insects and rate for protection crops"... etc. severely affected, changed or secondly poisons to be killed directly with other desert animals. Its ecological habitat to be changed and destroyed caused by human, and to be unbalance to their feed chains, among important reason is unplanned hunting take bring to a abnormal circle, so from the end of $60 \mathrm{~s}$ years to the $90 \mathrm{~s}$ years of $20^{\text {th }}$ century Wild Cat fur production almost face to non-production following decline with population.

Wild Cat's one original solitary population in some area, for example in eastern part of Tarim Basin and Lopnor lake region their vanished following with Xinjiang Tiger Panthera tigris lewcoqi final individual at the end of the $50 \mathrm{~s}$ of the $20^{\text {th }}$ century. Principal reason for cat resources decline can be abbreviated firstly is directly use by hunting, secondly is cultivated area's expanding and over measure mental exploiting, thirdly human population densely rising and following rise for life needs in all distribution area. Now impossible re-find Wild Cat tracks in out-shirts of some town and counties, villages and nearby $30-50 \mathrm{~km}$ by cultivated area, oases or fringe of desert as was original distribution area, if to compare it. Due to very rare Wild Cat it feed resource, from the end of the autumn to the end of the winter, poor populated Wild Cat have no choice but to enter some village residential areas or surrounding local farmland to catch and feed in poultry or small livestock, in that time that people regarded as an harmful animal by hunting. From the 1988 to now, the Wild Cat have been listed in "The Protected Wildlife of National Importance in China" (including all cat species) and fall into category II. From this time on the cat significance for it had been an guarantee position for security and protection. However the cat in some concentrated distribution areas and some high population of human, especially new exploitation and economical high tide developing region, anywhere oil and natural gas exploitation district and new residential area in Tarim Basin the cat condition exceed the protection limits to hunting continue, some populations face to the more the worsen. Appearances cat fur business, bargain and trade as like as skins of Wolves, Foxes, 


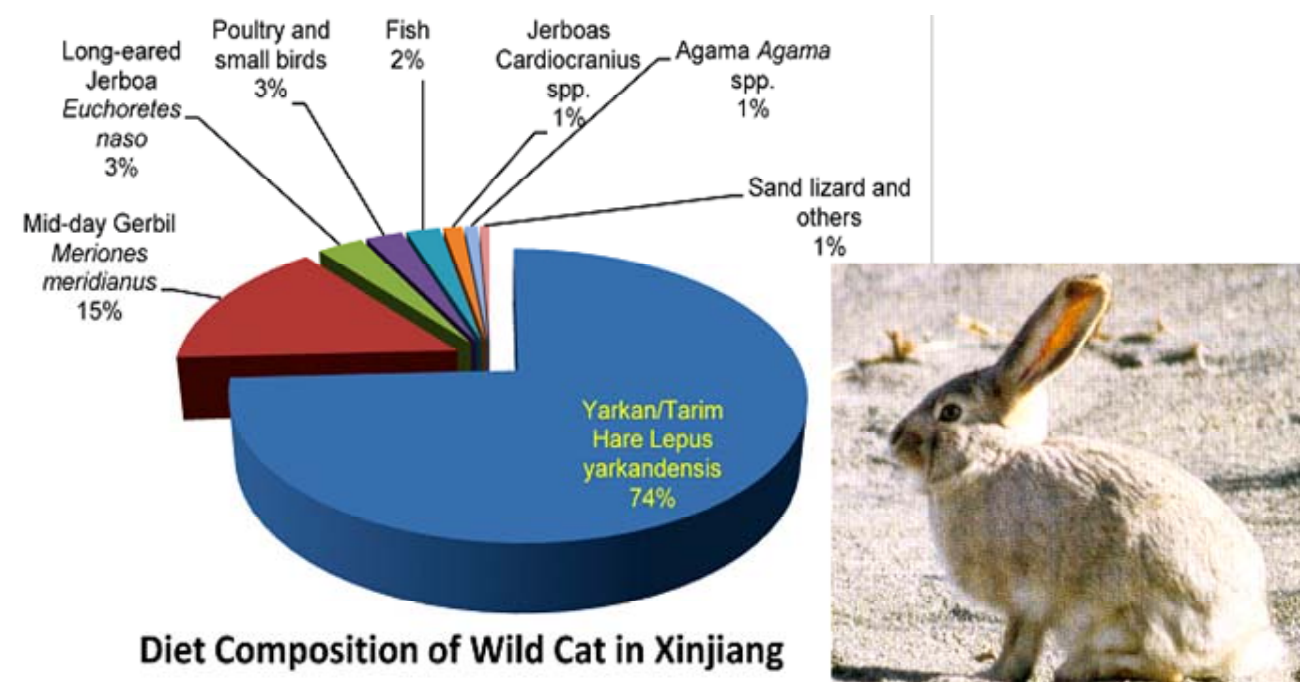

Figure 6. Components of different prey objects of Wild Cat in Xinjiang, China.

Table 1. Dynamics of foreign trade pelt collection of Wild Cat during last 40 years in three local regions in southern Xinjiang, China.

\begin{tabular}{ccccc}
\hline Year & Bayingolin & Aksu & Hotan & Total \\
\hline $1955-1959$ & 35 & - & 5678 & 5713 \\
$1960-1964$ & 7 & - & 3253 & 3260 \\
$1965-1969$ & 2432 & - & 1769 & 4201 \\
$1970-1974$ & 1638 & - & 1049 & 2687 \\
$1975-1979$ & 1672 & - & 753 & 2425 \\
$1980-1984$ & 1687 & - & 389 & 2076 \\
$1985-1989$ & 1107 & 210 & 240 & 1557 \\
$1990-1994$ & 45 & 206 & 180 & 431 \\
Total & 8623 & 416 & 13,311 & 22,350 \\
\hline
\end{tabular}

Marmot, Rabbit and livestock pelt trade eventually in Hotan, Kashkar and other some counties local market and bazaar.

At present in southern Xinjiang of China, only some fragmental distribution area for example flood-widening and populous covered parts and corridor areas of lower reaches of Hotan river valley, Yarkan river valley, Tarim river valley, Niya and Keriya river valley, Qarqan river valley keep in original distribution landscape habitat. But other any part especially nearby any new and old administration area or urbanized district for Wild Cat become dangerous points and position. To merge on Wild Cat this condition with hare is always same condition if to compare it. For this trend need some real approaches to formulae a policy and a concrete plan for protection efficacious urgently and further more need to study its on eco-biological and conservation biological research and on study evolutionary approach to clear all remain problems.

\section{CONCLUSIONS}

At present, only a few fragmented distribution areas, like flood plains, populous belts and green corridors in the lower reaches of Hotan, Yarkan, Tarim, Niya and Keriya, and Qarqan Rivers and riversides still serve as safe habitats for the wild cat within its original distribution range. Otherwise, several prior habitats, especially nearby new and old urban development zones, have become fragile and insecure places for the cat and its prey, the Tarim hare. Remaining small and fragmented population, the wild cat is fast declining in China probably due to habitat replace cotton and oilfield, acute shortage and scarcity of food, particularly during autumn and winter. The cat having no other options for survival, often intrudes into the rural residential areas and adjacent farmlands for food like domestic birds and small ruminants and so is killed ruthlessly. Although it has been listed as "Protected Wildlife of National Importance in China" under category II, guaranteeing its protection seemingly decreased fur trade in the local markets of Hotan, Kashqar and Bayingolin compared to that of wolves, foxes, marmots, and rabbits. The threat still continues in most of areas of its dense distribution range.

Rising human habitation near the new economically high-tide developing regions of Xinjiang perhaps due to extensive oil and natural gas exploration has caused the degradation of the last patches of its natural habitat. In order to impede and eventually reverse the deterioration of its natural habitat, formulation of appropriate policy actions is suggested that could foster effective protection of this elusive species in its original distribution range in the Xinjiang arid region of China.

\section{ACKNOWLEDGMENT}

This work is the results of financial aid as a special subject from Na- 
tional Natural Science Foundation of China (project №31071947). Dr. Urs Breitenmoser, Prof. Dr. Peter Vogel, Dr. Ryuichi Masuda and Dr. Satoshi Ohtaichi, IUCN/SSC Cat Specialist Group leader and members are work the period of the 1999 to 2004 and collaborative efforts between Xinjiang Institute of Ecology and Geography, Chinese Academy of Sciences and Hokkaido University of Japan. The Xinjiang Foreign Affairs Office, the Forest Bureau of Xinjiang and many local government offices especially protection management of nature, fauna and flora workers and officials assisted us in Urumqi, Turpan, Bayingolin, Awat, Kucha, Hotan, Niya, Qarqan, Qarkilik at local and we want to express our gratitude for their efforts and helpful hospitality.

\section{REFERENCES}

[1] Nowell, C. and Jackson, P. (1994) Wild cats-Status survey and conservation action plan. IUCN/SSC Press, Switzerland, 99.

[2] Ablimit, A., Hu, D.F. and Ruzi, A.M. (1994) Distribution and status of small and middle Wild Cats (Felidae) in inland region, Xinjiang. Acta Zoologica Arid Inland., Urumqi, 1, 50.

[3] Ablimit, A. (2004) Raptors and predators in Xinjiang. Xinjiang Scientific and Technology Press, Urumqi, 95.

[4] Allen, G.M. (1938) The mammals of China and Mongolia. Natural History of Centralasia, 11, 312-489.

[5] Ellerman, J.R. and Morrison-Scott, R.C.S. (1951) Cheeklist of Palearctic and Indian Mammals. British Museum of Natural History), London.

[6] Qian, Y.W., Zhang, J. (1965) Birds and mammals of Southern Xinjiang. China Scientific Press, 169-172.

[7] Shou, Z.-H. (1962) Economical animal fauna of China (Mammals). China Scientific Press, 86.

[8] Lin, Y.L. (1985) The mammals from Mt. Tomor Feng in Tianshan. Xinjiang People's Publishing House, 19.

[9] Gao, Y.T., et al. (1987) "FAUNA SINICA": Mammalia. Vol. 8 (Carnivora). China Scientific Press, 314.

[10] Liang, C.Q. (1986) Rare and endangered wildlife of Xinjiang. China Forestry Publishing House, 68.
[11] Ma, Y.Q. and Ma, Y. (1990). On the protection status of cats (Felidae). Chinese Journal of Wildlife, 4, 7-9.

[12] Hampton, R.E. (1994). Introductory biological statistics. Waveland Press Inc., Long Grove, 233.

[13] Ablimit, A., Anwar, M., Ma, M. and Yuan, H. (2004) Protected Wildlife of National Importance in Xinjiang, China. Xinjiang Scientific and Technology Press, Urumqi, 8 .

[14] Ablimit, A., Hu, D.F., Airat, M., Ruzi, B. and Talip, O. (1998) Distribution, resources and conservation strategies of Eurasian Lynx (Lynx lynx) in Xinjiang, China. Arid Zone Research, 3, 38-43.

[15] Ablimit, A. and Bekenov, A.B. (1995) General situation of Wild Cats (Felidae)in Kazakhstan. Acta Zoologica Arid Inland, 1, 327-329.

[16] Ablimit, A., Hu, D.F., Airat, M. and Ruzi, B. (1998) A systematic investigation and study on Asiatic Wild Cat (Felis silvestris ornata)'s eco-biological features and resources in Tarim Basin of Xinjiang, China. Arid Zone Research, 4, 20 .

[17] Gu, J.H. and Gao, X.Y. (1991) Animal fauna and Zoogeography of Eastern Kunlun-Altun Mountain/Studies on the Animals in Xinjiang. China Scientific Press, 30.

[18] Ablimit, A. and Airat, M. (1995) The protected wildlife of national importance in the Xinjiang. Arid Zone Research, 3, 11-22.

[19] (2007-2008) Xinjiang Meteorological Observatory, Xinjiang Annual Report (Unpublished).

[20] Xinjiang Geodesic Department (2007) The map of Xinjiang. Xinjiang People's Publishing House, 28.

[21] Ablimit, A. Anwar, M., Ma, M. and Yuan, H. (2004) Protected Wildlife of National Importance in Xinjiang, China (in Uygur). Xinjiang Scientific and Technology Press, Urumqi, 95.

[22] Ablimit, A., Babar, K., Ryuichi, M. and Satoshi, O. (2012) Asiatic wild cat (Felis silvestris ornata) is no more a "Least Concern" species in Xinjiang, China. Pakistan Journal of Wildlife, 1, 57-63. 